\title{
Biyoseramik kanal patı ile kontamine dentinde farklı kanal patı uzaklaştırma protokollerinin adezivin bağlanma dayanımı üzerine etkisi
}

\author{
Z. Gonca Bek Kürklü(0000-0002-4726-7883) ${ }^{\alpha}$, Zeynep Kasan(0000-0001-9972-4903) $)^{\beta}$, H. Oğuz Yoldaş(0000-0002-6887-1190) ${ }^{\gamma}$
}

Selcuk Dent J, 2020; 7: 170-173 (Doi: 10.15311/selcukdentj.454057)

Başvuru Tarihi: 16 Ağustos 2018 Yayına Kabul Tarihi: 02 Nisan 2019

öz Biyoseramik kanal patı ile kontamine dentinde farklı kanal patı
uzaklaştırma protokollerinin adezivin bağlanma dayanımı üzerine etkisi

Amaç: Adezivlerin dentine daha iyi bağlanabilmesi için kanal patının diş duvarından tamamen uzaklaştırıması gerekmektedir. Bu çalışmada farklı kanal patı uzaklaştırma protokollerinin tek aşama bir adezivin biyoseramik bir kanal patiyla kontamine dentine push-out bağlanma dayanımı üzerine etkisi araştırımışıı.

Gereç ve Yöntem: Alt 50 adet 2. premolar dişlere $3 \mathrm{~mm}$ çapında kök kanal giriş kaviteleri silindirik olacak biçimde açıldı. Bütün kanallar NiTi R25 Resiproc eğe (VDW, Almanya) ile şekillendirildi ve EndoSequence BC kanal patı (Brasseler, Amerika) ve gutta-perka ile dolduruldu. Kontrol gruplarındaki (Grup A) kök kanallarının dolumu yapılmadı bu sebeple koronal dentin yüzeyleri kanal patı ile kontamine olmadı. Kontrol grubu kavitelerinin restorasyonu G-Premio universal bond (GC Corp., Japonya) ve G-ænial kompozit (GC Corp., Japonya) ile yapıldı .Deney gruplarında giriş kavitesi dentin yüzeyleri EndoSequence BC ile kontamine edildi ve sonrasında kuru pamuk pelet (Grup B), distile su ile doymuş pamuk pelet (Grup C), $2 \mathrm{ml}$ distile su (Grup D) veya sulu ultrasonik enerii (Grup E) ile temizlendi. Kanal patının uzaklaştııımasından sonra, kavite yüzeyi adeziv ve kompozi trezin ile restore edildi. Her bir örnekten $1,5 \mathrm{~mm}$ kalınlığında oklüzalden servikale doğru horizontal olarak ikişer kesit alındı ve üniversal test cihazında push-out bağlanma dayanımları değerlendirildi.

Bulgular: En yüksek bağlanma dayanımı değerleri kontrol grubunda elde edilmiştir, bunu ultrasonik ile yıkama, su ile yıkama, ıslak pamuk ile silme ve kuru pamuk ile silme takip etmektedir. Kontrol grubu ile kuru pamuk ile silme grubu $(p=0.038)$ ve ultrasonik ile yıkama grubu ile kuru pamuklu ile silme grubu $(p=0.041)$ arasında anlamlı fark vardır.

Sonuç: Biyoseramik kanal patlarının bağlanma dayanımı kavite temizliğinde kullanılan su miktarı ile doğru oranda artmaktadır.

\section{ANAHTAR KELIMELER}

Adezyon, kompozit rezin, kök kanal patı

\section{ABSTRACT}

The efficacy of different sealer removal protocols on bond strength of adhesives to a bioseramic sealer contaminated dentin

Background: The optimal bonding of adhesives to dentin requires the sealer to be completely removed from dentinal walls. This study examined the influence of different sealer removal protocols on the push-out bond strengths of single step adhesives to a bioseramic root canal sealer contaminated dentin.

Methods: Diameter of $3 \mathrm{~mm}$ cylindrical root canal entry cavities were prepareted in the lower 2 nd premolar teeth. All of the root canals were prepared by R25 Reciproc NiTi files (VDW, Germany) and obturated with Endo Sequence BC Sealer (Brasseler, USA) and gutta-percha, Root canals in control groups were not obturated so coronal dentin surfaces were not contaminated with sealer. These cavities were restorated GPremio universal bond (GC Corp., Japan) and G-ænial posterior composite (GC Corp., Japan). For the experimental groups, dentin surfaces were contaminated with endosequence and wiped with dry cotton pellet, cotton pellet saturated with distile water, rinsed with $2 \mathrm{ml}$ distilled water, aqueous ultrasonic energy. After removal of the sealer, the surface of the cavity was restored with adhesive and composite resin. Specimens were sectioned horizontally with a thickness of $1.5 \mathrm{~mm}$ fo $r$ push-out bond strength evaluation. 2 sections were taken from the all specimens.

Results: The highest bond strength is in the control group, followed by ultrasonic rinsing, water rinsing, wet cotton wiping and dry cotton wiping. There was a significant difference between the control group and the dry cotton-wipe group ( $p=$ 0.038 ) and between the ultrasonic washing group and the dry cotton-wipe group $(p=0.041)$.

Conclusion: The better the bioceramic sealer is cleared and removed by water, the bond strength is increase.

\section{KEYWORDS}

Adhesion, composite resins, root canal sealer
Kök kanal tedavisinin başarısını arttırmada koronal sızıntıların önlenmesi restorasyonun ve kanal tedavisinin başarısı açısından önemlidir. ${ }^{1-9}$ Koronal restorasyon kök kanalının giriş kısmına ek bariyer oluşturarak ve pulpa odasını tıkayarak koronal yönden gelecek bakteri invazyonu, endotoksin ve tükrük infiltrasyonunu engeller. ${ }^{10}$

Kök kanal dolgusundan hemen sonra koronal sızdırmazlık için, nispeten uygulaması kolay ve teknik hassasiyeti az olan tek aşamalı adezivler

\footnotetext{
${ }^{\alpha}$ Çukurova Üniversitesi Diş Hekimliği Fakültesi Restoratif Diş Tedavisi Anabilim Dalı, Adana

$\beta$ Başkent Üniversitesi Adana Uygulama ve Araştırma Merkezi Diş Hekimliği Bölümü, Adana

${ }^{v}$ Çukurova Üniversitesi Diş Hekimliği Fakültesi Endodonti Anabilim Dall, Adana
} 
restorasyonlarda kullanılabilecek seçenekler arasındadır. ${ }^{11}$ Kök kanallarının doldurulmasından sonra kanal ağızlarının etrafında bulunan sertleşmemiş kanal patı artıkları tek aşamalı adeziv uygulaması sırasında, pulpa odası ve kavite duvarlarına yayılabilir. $\mathrm{Bu}$ artık patlar dişi boyayabilir, adezivin bağlantısını düşürebilir, kronun saydamlığını tehlikeye sokabilir ve hasta için estetik kaygılara yol açabilir. Rezin esaslı kanal patları veya öjenol içeren simanların kontaminasyonunun tek aşamalı adezivin bağlantısını olumsuz etkilediği bilinmektedir. ${ }^{12}$ Son yıllarda hayatımıza giren biyoseramik patlar; osteoindüktif etkisi, doku sıvıların varlığında sertleşebilmesi, kanala yerleştirildikten sonra uzun süreli antibakteriyel etkisi, sızdırmazlığı, uzun çalışma süresi, genleşerek kök kanalın içerisini boşluksuz doldurması ve tek kon tekniğini basitleştirmesi gibi özellikleriyle piyasaya sunulmuştur. ${ }^{13}$ Biyoseramik esaslı patlar kalsiyumsilikat-fosfat ve Mineral Trioksit Agregat (MTA) içerenler olarak sınıflandırılır. Biyoseramik esaslı kanal patlarının tek aşamalı adezivin bağlantısını nasıl etkilediği yönünde literatürde henüz bir araştırma bulunmamaktadır.

Borges ve ark. distile suya maruz bırakıldığında, biyoseramik esaslı patların yüzeylerinde kalsiyum ve karbon olarak çözünme gösterdiğini bildirmektedir. ${ }^{14}$ $\mathrm{Bu}$ araştırmada amaç, kalsiyum-silikat-fosfat içerikli (EndoSequence BC Sealer, Brasseler, Sanannah, Geoergia, ABD) bir biyoseramik kanal patı ile kontamine olmuş dentinin su ile temizlenmesinin, tek aşamalı adezivin yarattığı rezin-dentin bağlanma kuvvetine etkisinin incelenmesidir.

\section{GEREÇ VE YÖNTEM}

$\mathrm{Bu}$ in vitro çalışmada 50 adet alt 2. premolar insan çekilmiş dişleri kullanıldı. Dişler mikroskop altında incelenerek çürük, restorasyon veya çatlak olan dişler çalışmaya dahil edilmedi. Dişlerin kron diş boyu $8 \mathrm{~mm}$ ( $\pm 1 \mathrm{~mm})$, mesio-distal boyutu $7 \mathrm{~mm}( \pm 1 \mathrm{~mm})$ ve bukko-lingual boyutu $8 \mathrm{~mm}( \pm 1 \mathrm{~mm})$ aralıklarında olacak şekilde birbirine benzer boyutlarda dişler kullanıldı. Yüksek turda dönen el aleti ile su soğutması altında $3 \mathrm{~mm}$ çapında elmas bir fissür frez (meisinger, 837LG,050, Almanya) yardımıyla endodontik kök kanal giriş kaviteleri silindirik biçimde olacak şekilde ve birbirleri ile aynı çapta ( $3 \mathrm{~mm} \pm 0,2 \mathrm{~mm}$ ) açıldı.

10 numaralı K-tipi el eğesi, ucu apeksten görününceye kadar kök kanalı boyunca ilerletildi. Kanal boyu belirlendi ve çalışma boyu bu boydan $1 \mathrm{~mm}$ kısa olacak şekilde tespit edildi. Kök kanalları, R25 Reciproc eğesi (VDW, Münih, Almanya) ile endodontik motor (Silver Reciproc motor, VDW, Münih, Almanya) kullanılarak şekillendirildi. Preparasyon sırasında irrigasyon amaçlı $2.5 \mathrm{ml} \% 5.25$ 'lik $\mathrm{NaOCl}$ solüsyonu (Sultan Chemists Inc.,Englewood, New Jersey, USA) kullanıldı. Son yıkama için kök kanallarının içerisinde bulunan debrisi ve yıkama solüsyonlarının etkisini kaldırmak amacıyla $5 \mathrm{ml}$ distile su kullanıldı. Daha sonra kök kanalları kâğıt konlarla (Spident, NamDongKongDon, Inchon, Korea) kurulandı. Dişler 5 gruba rastgele dağıtıldı $(n=10)$. Kontrol grubu kavitesi kanal patıyla kontamine edilmedi ve üretici talimatlarına göre tek aşamalı üniversal adeziv (G-Premio BOND, GC Corp., Tokyo, Japonya) ve kompozit rezinle (G-ænial posterior, GC Corp., Tokyo, Japonya) restore edildi. Diğer 4 gruptaki dişler direkt kullanıma hazır enjektör yardımıyla Endosequence BC Sealer (Brasseler, Savannah, GA, Amerika) ve tek kon gutta-perka (Reciproc gutta-perchac ones R25, VDW, Münih, Almanya) tekniğiyle dolduruldu. Kanal patı sertleşmeden 1 saat içerisinde $B$ grubunda sertleşmemiş kanal patı artıkları kavite içinden kuru bir pamuk palet yardımıla uzaklaştıııldı. C grubunda artık pat ıslak bir pamuk palet yardımıyla uzaklaştırıldı. D grubunda kavite $2 \mathrm{vml}$ distile su ile enjektörle yıkandı. E grubunda kavite içine $1 \mathrm{dk}$ boyunca sulu ultrasonik enerji uygulandı.

Kanal patının uzaklaştırılması işlemi sonrası kontrol grubu ile aynı şekilde tüm diğer gruplara da kavite yüzeyine tek aşamalı üniversal adeziv uygulandı ve kompozit rezinle restore edildi.

Örnekler $37{ }^{\circ} \mathrm{C}$ 'de 24 saat nemli ortamda bekletildi. Restore edilmiş diş kronunun oklüzalinin en derin noktasının $1 \mathrm{~mm}$ altından başlayarak su soğutmalı kesme cihazı (Exakt $300 \mathrm{cl}$ Apparatebau, Norderstedt, Almanya) kullanılarak yaklaşık 1,5 mm kalınlığında horizontal 2 kesit alındı. Push-out kuvveti, kesitlere $1 \mathrm{~mm} /$ dakika hız ile üniversal test cihazı (Testometric Company Ltd, Rochdale, Lancashire, Ingiltere) kullanılarak uygulandı. Elde edilen değerler MPa'a çevrildi. 10 tekerrürlü deneme ile kesitlerin ortalamaları alındı. Ortalamalardan her gruptaki en küçük ve en büyük iki değer atılarak tekerrür sayısı 8'e indirildi. Push-out bağlanma dayanımı değerleri normal dağılış gösterdiği için tek yönlü varyans analizi (ANOVA) ve TUKEY çoklu karşılaştırma testi ile grup ortalamaları ikişerli olarak karşılaştırıldı (IBM SPSS Statistics V21 Armonk, Amerika).

\section{BULGULAR}

Push-out bağlanma dayanımı sonuçları Tablo 1 ve Şekil 1'de gösterilmiştir. 5 grup için bağlanma dayanımları, kontrol grubu (Grup A), kuru pamuk (Grup B), Islak pamuk (Grup C), su ile yıkama (Grup D), ultrasonik ile yıkama (Grup E), sırasıyla 11.13, 5.23, 7.51, 8.41, 10.73 MPa.'dır. En yüksek bağlanma dayanımı kontrol grubunda, ardından sırası ile ultrasonik ile yıkama, su ile yıkama, ıslak pamuk ile silme ve kuru pamuk ile silme gruplarında olduğu bulunmuştur. Kontrol grubu ile kuru pamukla silme grubu arasında $(p=0.038)$ ve ultrasonik ile yıkama grubu ile kuru pamukla silme grubu arasında $(p=0.041)$ istatistiksel olarak anlamlı farklıık vardır. Kontamine olmamış kontrol grubu ile ultrasonik ile yıkama, ıslak pamuk ile silme ve su ile yıkama grupları arasında istatistiksel olarak anlamlı bir fark yoktur ( $p>0.05)$. 
Tablo 1.

\section{Ortalama Push-out bağlanma dayanımı değerleri (MPa) ve standart sapmaları}

\begin{tabular}{|lcccc|}
\hline GRUPLAR & N & Ortalama & Std. Sap. & $\begin{array}{c}\text { Homojen } \\
\text { altkümeler } \\
\text { * }\end{array}$ \\
\hline Kontrol (Grup A) & 8 & 41579 & +4.7 & B \\
\hline Kuru pamuk (Grup B) & 8 & 45047 & +1.01 & $\mathrm{~A}$ \\
\hline Islak pamuk (Grup C) & 8 & 18810 & +0.88 & $\mathrm{AB}$ \\
\hline $\begin{array}{l}\text { Su ile yıkama (Grup D) } \\
\text { Ultrasonik ile yıkama (Grup }\end{array}$ & 8 & 15189 & +2.10 & $\mathrm{AB}$ \\
\hline E) & 8 & 26938 & +7.39 & $\mathrm{~B}$ \\
\hline
\end{tabular}

* Farklı harfler, ortalama farkın .05 seviyesinde anlamlı olduğunu gösterir.

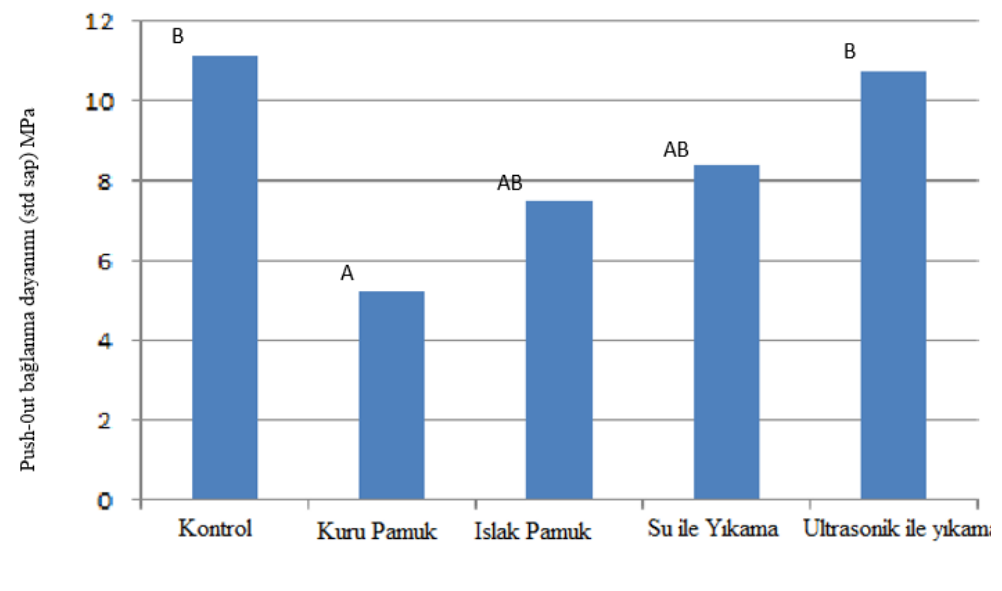

* Farklı harfler, ortalama farkın $\mathrm{p}<0.05$ seviyesinde anlamlı olduğunu gösterir.

Şekil 1.

Ortalama Push-out bağlanma dayanımı değerleri (MPa) ve standart sapmaları

\section{TARTIŞMA}

Kanal patı ile kontamine dentini değerlendiren çalışmalarda, dişlerden düz dentin yüzeyi elde edilmiştir. ${ }^{15,16,17}$ Bağlanma dayanımı değerlendiren çalışmalarda düz dentin yüzeyi-adeziv bağlantısına gerilim/mikrogerilim testi uygulanmıştır. ${ }^{15,16}$ Fakat düz dentin yüzeyi klinikte kullanılan kavite şartlarını taklit etmemektedir.

Çalışmamızda klinikte kullanılan kavite dizaynını taklit edebilmek için alt premolar dişlere $3 \mathrm{~mm}( \pm 0,2 \mathrm{~mm}$ ) çapında silindirik sınıf I kaviteler açılarak kök kanalına ulaşılmıştır. Push-out testi, yaygın olarak silindirik kanal içi malzemesinin bağlanma kuvvetini ölçmek için uygulanmaktadır. ${ }^{18-20}$ Benzer şekilde bu araştırmada silindirik rezin-dentin örneklerinin bağlantısı değerlendirmek için push-out bağlanma dayanımı testi kullanılmıştır.

Çalışmalar rezin esaslı kanal patının varlığının tek aşamalı adezivlerin dentine bağlantısını düşürdüğü göstermiştir. ${ }^{15-16}$ Rezin esaslı patlarda artık patın kaviteden uzaklaştırılması için etanol, alkol, aseton, etil asetat gibi kimyasal çözücülere intiyaç vardır. ${ }^{18,19} \mathrm{Bu}$ çözücüler de adezivin dentine bağlantısına olumsuz etki etmektedirler. Bioseramik patların ve rezin esaslı patın biyoseramik ve rezin esaslı patların suda çözünürlüğünün kıyaslandığı bir çalışmada biyoseramik patların suda çözünürlüğünün yüksek olduğu belirtilmiştir. ${ }^{21}$

$\mathrm{Bu}$ nedenle mevcut çalışmada biyoseramik esaslı Endosequence BC Sealer Patı ile kontamine olmuş koronal dentinin su ile temizlenmesini değerlendirilmiştir.

Esas bileşenleri kalsiyum silikat ve hidroksiapatit olan Endosequence BC Sealer patı hidrofiliktir. Artık pat kavite dentininden tamamen uzaklaştırılamasa bile dentin tübülündeki ve kavitedeki suyu emerek dentine bağlanır. Kaviteyi su ile yıkamak veya silmek rezindentin bağlantısını olumsuz etkilememiştir.

Tek aşamalı üniversal adeziv kullanarak koronal sızdırmazlık oluşturabilmek için Endosequence BC Sealer ile kontamine edilmiş dentini temizlemede kuru pamuk pelet kullanımı diğer gruplardaki temizleme yöntemlerine göre daha az etki göstermiştir. Bunun muhtemel sebebi kanal patının doldurucu bileşenleri yüksek oranda rezindentin ara yüzleri içinde bulunması olabilir. Bu konu üzerinde ileri araştırmalar yapılması faydalı olacaktır.

\section{SONUÇ}

Giriş kavitesinde artık olarak kalan ve polimerizasyonunu tamamlamamış kanal dolgu patları dentin adeziv sistemlerin bağlantısını etkilemektedirler. Farklı kanal patlarını uzaklaştırmada çeşitli yöntemler kullanılmaktadır. Biyoseramik kanal patlarının giriş kavitesinden uzaklaştırmada kullanılan su miktarı arttıkça giriş kavitesindeki kanal patı daha iyi elimine edilmekte ve bu durumda dentin adeziv sistemlerin ve kompozit restorasyonun bağlantısını artırmaktadır. 


\section{KAYNAKLAR}

1. Swanson K, Madison S. An evaluation of coronal microleakage in endodontically treated teeth. Part I. Time periods. J Endod 1987; 13: 56-9.

2. Ray HA, TropeM. Periapical status of endodontically treated teeth in relation to the technical quality of the root filling and the coronal restoration. Int Endod J 1995; 28 : 12-8.

3. Tronstad L, Asbjørnsen K, Døving L, Pedersen I, Eriksen HM. Influence of coronalrestorations on the periapical health of endodontically treated teeth. Endod Dent Traumatol 2000; 16: 218-21.

4. Hommez GM, Coppens CR, De Moor RJ. Periapical health related to the quality of coronal restorations and root fillings. Int Endod J 2002; 35: 680-9.

5. Heling I, Gorfil C, Slutzky H, Kopolovic K, Zalkind M, Slutzky-Goldberg I. Endodontic failure caused by inadequate restorative procedures: review and treatment recommendations. J Prosthet Dent 2002; 87: 674-8.

6. Iqbal MK, Johansson AA, Akeel RF, Bergenholtz A, Omar R. A retrospective analysis of factors associated with the periapical status of restored, endodontically treated teeth. Int J Prosthodont 2003; 16: 31-8.

7. Siqueira JF Jr, Rôças IN, Alves FR, Campos LC. Periradicular status related to the quality of coronal restorations and root canal fillings in a Brazilian population. Oral Surg OralMed Oral Pathol Oral Radiol Endod 2005; 100: 369-74.

8. Sabeti MA, Nekofar M, Motahhary P, Ghandi M, Simon $\mathrm{JH}$. Healing of apical periodontitis after endodontic treatment with and without obturation in dogs. J Endod 2006; 32: 628-33.

9. Ng YL, Mann V, Rahbaran S, Lewsey J, Gulabivala K. Outcome of primary root canalt reatment: systematic review of the literature-Part 2. Influence of clinical factors. Int Endod J 2008; 41: 6-31.

10.Wolanek GA, Loushine RJ, Weller RN, Kimbrough WF, Volkmann KR. Invitro bacterial penetration of endodontically treated teeth coronally sealed with a dentin agent. J Endod2001; 27: 354-7.

11.Korasli D, Ziraman F, Ozyurt P, Cehreli SB. Microleakage of self-etch primer/adhesives in endodontically treated teeth. J Am Dent Assoc 2007; 138: $634-40$.

12.Peutzfeldt A, Asmussen E. Influence of eugenolcontaining temporary cement on bonding of self-etching adhesives to dentin. J Adhes Dent 2006; 8: 31-4.

13.Tyagi S, Mishra P, Tyagi P. Evolution of root canal sealers: An insight story. Eur J Gen Dent 2013; 2: 199218.

14.Borges RP, Sousa-Neto MD, Versiani MA, RachedJúnior FA, DeDeus G, Miranda CE, Pécora JD. Changes in the surface of four calcium silicate-containing endodontic materials and an epoxy resin-based after a solubility test. Int Endod J 2012; 45: 419-28.
15.Topçuoğlu HS, Demirbuga S, Pala K, Cayabatmaz M, Topçuoğlu G. The bond strength of adhesive resins to $\mathrm{AH}$ plus contaminated dentin cleaned by various guttapercha solvents. Scanning2015; 37: 138-44.

16. Roberts S, Kim JR, Gu LS, Kim YK, Mitchell QM, Pashley DH, Tay FR. The efficacy of different sealer removal protocols on bonding of selfetching adhesives to $\mathrm{AH}$ plus contaminated dentin. J Endod 2009; 35: 563-7

17.Kuga MC, Faria G, Rossi MA, do CarmoMonteiro JC, Bonetti-Filho I, Berbert FL, Keine KC, Só MV. Persistence of epoxy based sealer residues in dentin treated with different chemical removal protocols. Scanning 2013; 35: 17-21.

18.Fisher MA, Berzins DW, Bahcall JK. An in vitro comparison of bond strength of various obturation materials to root canal dentin using a push-out test design. J Endod 2007; 33: 856-8.

19. Kremeier K, Fasen L, Klaiber B, Hofmann N. Influence of endodontic post type (glass fiber, quartz fiber orgold) and luting material on pushout bond strength to dentin in vitro. Dent Mater 2008; 24: 660-6.

20.Stiegemeier D, Baumgartner JC, Ferracane J. Comparison of push-out bond strengths of Resilon with three different sealers. J Endod 2010; 36: 318-21.

21.Borges RP1, Sousa-Neto MD, Versiani MA, Rached-Júnior FA, De-Deus G, Miranda CE, Pécora JD. Changes in the surface of four calcium silicate containing endodontic materials and an epoxy resin-based seale rafter a solubility test. Int Endod J 2012; 45: 419-28.

Yazışma Adresi:

Z. Gonca BEK KÜRKLÜ

Çukurova Üniversitesi Diş Hekimliği Fakültesi

Restoratif Diş Tedavisi AD

Sarıçam, Adana

Tel : +90 5334500892

E Posta: goncabek@mynet.com 